\title{
Encouraging energy efficiency in united kingdom independent retail? the The case of the butcher, fishmonger and cycle-shop
}

\author{
David Kenington, Lai Fong Chiu, Kathryn B. Janda, Paul Ruyssevelt
}

University College London, United Kingdom

\begin{abstract}
The UK non-domestic sector accounts for $16 \%$ of energy use and major cuts are needed to meet a 'net zero' $\mathrm{CO}_{2}$ emissions target by 2050 . Policy and research to date have focused on technical potential and there are gaps in understanding social contexts, which are key to energy efficiency improvement. Furthermore, SMEs have been overlooked, despite the need for concerted action here to meet targets. In this study, mixed-method case study research is undertaken with three independent retailers (a butcher, fishmonger and cycle-shop) to explore energy management and energy efficiency adoption. Building on the 4Cs "Concern, Conditions and Capacity within a Community" (4Cs) framework developed by Janda, this study has identified the interrelationships between Cs and explored the underlying factors that appear the be more important in determining responses to energy efficiency opportunities. Reflecting on the 4Cs, improving energy efficiency within this sector is complex, so it is perhaps not surprising that energy efficiency adoption has been low to date. This study highlights the importance of the 'social' within a socio-technical context. Whilst technical conditions are invariably the most important factor in engineering calculations of energy efficiency potential, they appear to be of considerably less importance than social contexts in practice. The findings suggest that a greater focus on social context within a socio-technical frame could help make future policy interventions more effective. Whilst some of these findings may be sector-specific, several are likely to be transferable to other SMEs, retail and hospitality organisations.
\end{abstract}

Keywords: Energy; Energy efficiency; Non-domestic; Retail; Small businesses; Case study; Mixed-methods; Socio-technical

\section{Introduction}


Small to medium enterprises (SMEs) are responsible for $13 \%$ of global energy deman[Instruction: Overall comments:

KJ comment: Is it weird that the numbered references are out of sequence? The bibliography is alphabetized, so the numbers are out of sequence. This was not the case in previous ERSS articles I've written, not sure whether it is a glitch here.]d [29] and significant abatement potential exists among United Kingdom SMEs according to recent UK Government research [15]. However energy efficiency adoption rates are low and there is a lack of understanding as to why this is the case [3,21,22].

Most research to inform potential and abatement options has followed distinct physical, technical and economic approaches to date $[6,39]$. However, the problem has been shown to be a much more complex sociotechnical one [28,30,32,37,40]. The 'social' aspects of energy efficiency adoption have been understudied [3], and understanding of how they interplay with the 'technical' is thought to be key to delivering the step-change required to meet emissions reduction targets [13,17,34]. Janda proposed the 4Cs framework "concern, capacity and conditions within building communities" which considers social and technical issues to help inform different types of policy interventions and their likely effectiveness [34].

The purpose of this study was to explore energy management and energy efficiency adoption within independent retailers to help inform policy and future research. The study used a mixed-methods case study research approach (including on-site in-depth interviews and energy audits) with three independent high street retailers, considering social and technical issues.

The research findings were analysed using the 4Cs framework, adapted to make it appropriate for small, owner-operated independent retailers. This work contributes to the literature by augmenting the framework to tailor it for this subgroup with the goal of better informing policy for these "hard-to-reach" business populations.

The paper begins with a literature review which notes that little work has been done to date on small independent retailers. Next, it describes the origin and evolution of the 4Cs framework. Then it describes the research design and methods used to address three different examples of small independent retailers. The findings section profiles each retailer, then uses the 4Cs framework to organise themes found within the research. The discussion considers policy implications and future research, including further development of an energy efficiency adoption framework tailored to small independent retailers.

\section{Literature review}

\subsection{Context}

The UK Government Building Energy Efficiency Survey [15], estimated that retail energy use comprises 17\% of the non-domestic sector $(27,340 \mathrm{GWh} / \mathrm{a})$, of which small shops (the majority of which are independent retailers $^{1}$ ) comprise the largest sub-sector $(11,600 \mathrm{GWh}, 42 \%$ of total). The study also estimated large energy abatement potential of $34 \%(9420 \mathrm{GWh})$ for retail.

SME energy management has been defined as a broad set of activities, including habitual energy-using behaviours, billing/contracting, equipment maintenance/replacement and premises refurbishment and 
abatement opportunities exist across all of them ([15], Citiz[Instruction: Reference 12 should be Citizens Advice, not C. Advice as currently shown.]ens [12,22,50]).

Numerous studies describe a range of barriers to adoption of energy efficiency measures, including costs and access to capital, lack of knowledge, time and resources, energy management responsibilities, and split incentives, [1,5,14]. Barriers vary across sectors and geographies, although observed take up is low, even for very cost effective measures [49]. However, the concept of drivers and barriers in this context has been criticised, arguing that they fundamentally misunderstand organisational behaviour by assuming they are 'rational' economic actors [2]. Understanding organisational behaviour as the outcome of a much wider set of socio-technical factors offers a more useful approach, which can more effectively inform policy [30,32,37,40].

Very few studies have explored SMEs from this perspective (none which include independent retail), with one or two notable exceptions; Janda, whose 4Cs conceptual framework this project utilises and Hampton [27,28 [30]].[Instruction: I added this reference here too, but need to remove the open bracket before 30 - sorry didnt know how to do that.] Hampton looked at SME energy management from a social practice perspective, showing that energy management is highly complex and woven into the culture and practices of small organisations, and is influenced by the ongoing sensemaking processes which give organisations their character. Because of this, the ways in which existing policy interventions, such as energy audits and advice can influence organisations are often unpredictable and unexpected. He recommends further, collaborative research, such as action research using these methods to better understand how to engage SMEs and help them usefully improve how they manage energy.

\subsection{Approach}

Business activities and energy use are very heterogeneous [15] and similar organisations can use very different amounts of energy, whereas seemingly different organisations can appear to have similarities [32]. Considering the complexity of issues described above, use of traditional research approaches (i.e. technical or social) have struggled to explain this [32]. In response to electricity blackouts in California in 2000 and 2001, Janda et al. [32] and Lutzenhiser et al. [40] developed a heuristic framework called "3Cs" in order to better explain such phenomena by considering social and technical issues together. These include various relevant actors (e.g. occupants, organisations, landlords, agents, buildings, equipment) and relationships between people, energy and buildings [56](Berensen, 2002). The framework describes that energy efficiency actions are dependent on 3Cs - "Concern" (within organisations about energy efficiency relative to other goals), "Capacity" of organisations to act and "Conditions" - real-world conditions at their premises that are to be acted upon. Recognising the lack of nuance and interdependence of the factors in reality, Janda [34] further developed the 3Cs framework to 4Cs, including a 'building communities' aspect (Fig. 1). This recognizes the units of analysis commonly used in business settings (either organisations or individuals) and therefore helps to accommodate the perspectives of building stakeholders at different levels, for example, occupants, building managers, organisation ownership and senior management. The 4Cs framework also points to "grey" areas above, below, and between individual employee and organisational levels that additionally influence work context and decision-making, for example, public acceptance, professional institutions and public policies [7, 34].[Instruction: Fig 1 needs to be moved to this section (section 2.2)] 


\subsection{Extending the 4Cs framework for SMEs}

This study concerns independent retailers who generally are 'owner-operated', meaning that the organisation, building managers and users are often the same people. Therefore, the 4Cs framework has been adapted for use in SMEs by narrowing the "community" dimension of stakeholder analysis. This study also augments the 4 Cs by considering the role of time and other factors.

\section{Research design \& methods: a case study of three independent retailers}

A case study method was selected for this study, using three cases and a mix of methods within each case, due to the exploratory nature of the objectives and informed by previous similar work in other sectors $[11,37,38,55$ ]. Case-studies are useful for theory building through deepening understanding of the causes of problems and their consequences $[19,23]$. Furthermore, buildings and energy related research which considers issues from a socio-technical perspective have been shown to help inform policy interventions more effectively than previous work [11,55]. Such methods have not been employed in this sector extensively, and so were used here to help understand issues for independent retailers, but also considering that similar issues may be relevant to other businesses.

Informed by Lowe et al's socio-technical case study method [38], the research design was pragmatic, with the selected premises providing physical boundaries and structure for the exploration of relevant social components relevant to better understanding energy management. Three retailers with different energy use profiles were selected as study cases, sampled purposively and conveniently, comprising a butcher, fishmonger (both with relatively high energy use) and a cycle-shop (with lower energy use) [48,55]. The retailers were all located in London, on the same high street and local to the researchers' home. Two were close neighbours, and the other one was located approximately half a mile further up the street, within another parade of shops. Each of the premises had similar floor areas $\left(135-170 \mathrm{~m}^{2}\right)$ and construction types (Victorian, Post-war). One retailer was recruited through a pre-existing relationship to the researcher (an ex-neighbour). The other two retailers were recruited through approaching them directly, asking to speak to the owner about the project, selecting a quiet time of day (early morning, or before lunchtime) to minimise the likelihood of rejection due to the need to serve customers. Both were open to the idea once the project, and their involvement (including time commitments) had been explained. No other retailers were approached as no rejections to participate occurred (although this was considered as a risk, and plans were made to recruit more if so). The opportunity to have their energy use examined and having the opportunity to discuss ideas about how to reduce energy costs were key reasons for participation. Furthermore, the knowledge that the researcher was from the local area and that other local retailers were participating also appeared to encourage participation.

A staged design was employed to enable a 'quasi-intervention ${ }^{2}$ ' approach to be taken, whereby building characteristics, energy using equipment and energy use data could be collected to inform an energy audit, from which energy efficiency actions could be identified and discussed with participants. By exploring internal and external business contexts and physical conditions within the shops in the first stage, also enabled such factors to be considered as part of exploring energy efficiency opportunities. This helped to qualitatively explore the 
role of such issues in helping overcome barriers to taking action on energy efficiency. The research comprised three stages, occurring over a period of eight weeks during summer 2017 (Fig. 2).[Instruction: Fig 2 needs to be moved to here.]

The sampling strategy was informed by previous research $[15,44]$. Participation encouraged through clear description of the research purpose and offer of feedback within the follow-up interviews which may have helped inform energy-bill savings. Risk of drop out across stages was mitigated through a) using a face to face approach, which helped to develop rapport with participants and b) being flexible on when interviews were undertaken, identifying times of day which tended to be quieter, for example in terms of customer footfall. Being on-site also enabled the researcher to be sensitive to the varying and unpredictable nature of shopkeeping, for example encouraging participants to feel comfortable to pause the discussion and tend to customers/other issues as and when needed.

Stage 1: Stage 1 included (a) quantitative data collection of building characteristics and energy-using equipment on-site and billing/meter data (where possible) and (b) face-to-face semi-structured interviews with owner/managers, using an on-site 'walk through' procedure. In practice, this consisted of a hybrid-approach of quantitative data collection and qualitative interviewing within the same initial visit, with a detailed topic guide and data collection sheet designed for this purpose. At the same time as documenting and photographing building characteristics and energy using equipment, the walkthrough procedure was used to enable participants to describe and discuss business and energy management activities. As described by Chiu et al, [11] the procedure is a visual/spatial technique which has the advantage of evoking a rich description of activities and related issues, associated with specific equipment / building fabric. Furthermore, elements of ethnography [24] were also used to observe relevant energy using behaviours on-site and record issues by taking photographs. Stage 1 interviews lasted typically one hour, although it varied as interviews were paused from time to time to allow participants to tend to shop-keeping activities (e.g. serving customers).

Stage 2: Stage 2 included analysis of stage 1 findings, which included an assessment of energy use and identification of energy efficiency opportunities using a small business energy audit tool [52]. Data collected in stage 1 facilitated a bottom-up calculation of energy use, which was then reconciled against meter readings taken over the fieldwork period [10,41]. For equipment where name-plate ratings were visible, these were recorded, and industry estimates of load factors were used to assess energy use. Where these were not available, desk research was undertaken to estimate energy use, using sources including Market Transformation Programme stock energy use data [42,43]. Estimates of energy efficiency potential were informed by a desk review of equivalent, efficient equipment available on the market, informed by sources including the Energy Technologies List [16]. The assessments were limited by data quality (mainly based on participant billing estimates and a bottom-up assessment of energy use). Unfortunately, none of the retailers were able to provide access to energy bills.

Stage 3: Stage 3 comprised follow-up face to face semi-structured interviews with owner/managers to discuss energy efficiency opportunities and barriers, informed by preceding stages. To mitigate participant burden, a limited number of opportunities were presented to participants for discussion (see example, shown in Table 3). These were purposively selected exploring a range of intervention types, 
selected based on their scale, relevance to participants (informed by stages 1 and 2) and theoretical sensitivity [9]. These interviews were conducted on-site, utilising the same 'walk-through' process, focused on a sub-set of shop areas, relevant to the discussion, lasting about 30-45 min 45 minutes. [Instruction: I'd tend to use minutes in full here, but happy to go with your edit if this is the standard approach.]

All interviews were digitally recorded where possible (however, some refused recording on the basis of the likely presence of customers who may object) and transcribed verbatim for analysis.

\subsection{Analysis}

Data collection, quantitative and qualitative analysis were undertaken iteratively and in parallel enabling ideas and issues to be further explored during data collection [51] to inform analysis. Field notes were taken at the time of interviews and site visits, as a running commentary throughout the research to capture insights and observations felt to be important to the findings. This helped to ensure continuity and comprehensiveness as multiple fieldwork visits were undertaken at different times. Transcripts, field notes and corresponding photographs were sorted into cases. An analytical framework using a series of matrices in MS Excel was used to contrast physical arrangements and quantitative (e.g. energy using equipment and use) data with participant in-depth interview data ([38]: 478-479). The framework was used as a basis for cross-case comparison and analysis. Between and subsequent to fieldwork stages, meetings were held between the researchers to discuss emerging findings and the focus for the analysis before writing up each case report.

\subsection{Limitations}

Case study methods are resource intensive, so the research was limited by its scope, scale and timescales, which was limited to a six-week period in summer 2017. It would likely have been insightful to expand the research to include a longer timescale (e.g. across different seasons) and other types of retailers. It would also have been beneficial to include supply chain actors (e.g. equipment suppliers, maintenance contractors and electricians) within the research.

Case studies have been criticised for being limited in their ability to generalise findings, however this has been challenged by others who argue that context dependent case studies are likely to produce useful theory and that the value of case studies are enhanced in the careful choice of cases and design $[19,23,54]$. These challenges were considered in the sampling approach, for example purposively sampling three cases, which were reasonably typical of many independent retailers, (although acknowledging the heterogeneity of the sector). They also varied in terms of energy intensity, but were similar in other aspects such as geography and size. As such, whilst some of the findings may be sector-specific, several are likely to be transferable to other parts of the non-domestic sector, such as broader retail, hospitality and other SMEs.

\section{Findings}

This section commences with an overview of the retailers included in the research and their energy profiles, including identification of energy efficiency opportunities. This is then followed by a discussion of the findings in Section 5, conclusion and recommendations, including policy implications in Section 6- and poliey 
implieations in Seetion 7. The findings were informed by the analysis process described above, and the 4Cs conceptual framework bounds the investigation.

\subsection{Retailer profiles}

Each retailer was owner-managed, with 2-3 staff in total who all performed sales, operations or technical roles. In all cases, owners took responsibility for energy issues and led energy management activities. The owners of the cycle-shop and fishmonger were mid-career and planning to stay in the business for the long term, whereas the butcher was semi-retired and gradually reducing his role over time. For all retailers, most customers came through 'walk-in's' off the street, driven by location, reputation and repeat business. All claimed a local presence/loyal customer-base, despite stiff competition from retail chains and supermarkets. " $I$ know many of my customers going back many years and we see each other as friends" (Fishmonger). Retaining and attracting new local custom "coming in off the street" was seen as the main business opportunity across all retailers. This meant that ensuring the premises were attractive and welcoming to customers was paramount and this had clear implications for energy efficiency adoption, which is discussed below. Challenges facing retailers included costs (staff, stock and operations), competition from larger retailers and local practical issues, such as parking. Energy costs (Table 2)[Instruction: Rather than table 2 - this should actually reference the three pie charts (which I have asked to be given a figure number). Could this reference to table 2 be updated to that once the pie charts have a figure number please?] were noted prominently by the fishmonger and butcher "after staff, rent and fish, energy is my greatest cost" (Fishmonger).

Summary energy profiles are shown in Table 2.[Instruction: As above - could this reference be changed from table 2 to the new figure, which will link to the three pie charts?] Across each retailer, the energy audits identified significant energy efficiency potential (Tables 1, 3), ranging from behavioural changes to equipment replacement and fabric upgrades. Estimated energy-bill savings ranged between $14 \%$ and $57 \%{ }^{3}=$ The Butcher's potential was very high, principally because all the refrigeration and air-conditioning equipment onsite was over 20-years old and inefficient (Table 2, Fig. 3). [Instruction: As you can see from the comments above, I have asked for this to be cited in a couple of places, in place of citing Table 2. I have tried to actually do this, using the citation tool, but I cannot check the citation box for this figure as it is greyed out (I might be doing something silly, but I couldnt work it out) - I hope from the comments above it is clear where the citations for this figure ought to be.]

alt-text: Unlabelled image

Figure Replacement Requested 

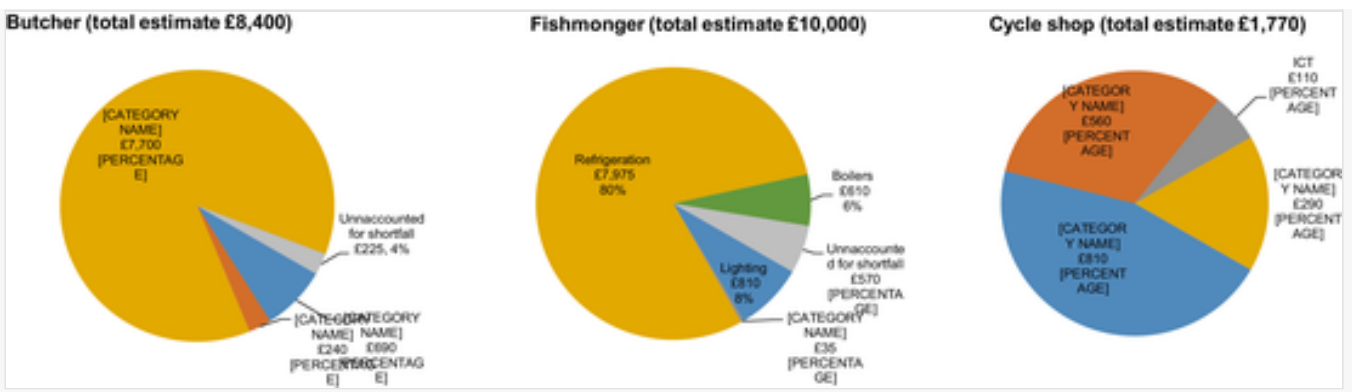

\section{Replacement Image: Energy profiles pie charts.docx}

Replacement Instruction: Could these three charts be called Figure 3? I have attached a word doc with the correct figures and labeling of the segments in each pie chart (they have gone awry in the current proof). Finally, in the current page layout the pie chart on the right hand side (cycle shop) is hidden. Could they be moved to the top of the page and span the whole width of the page, such that it is no longer hidden? If that doesnt work, please do suggest an alternative arrangement which would fit them all on the page (and still be within this section and near tables 1,2 and 3 .

alt-text: Table 1

Table 1

(i) The presentation of Tables and the formatting of text in the online proof do not match the final output, though the data is the same. To preview the actual presentation, view the Proof.

Estimated annual energy bills and estimated savings from energy efficiency opportunities.

\begin{tabular}{|l|l|l|l|}
\hline Retailer & $\begin{array}{l}\text { Estimated energy bill } \\
\text { (£/annum) }\end{array}$ & $\begin{array}{l}\text { Estimated energy efficiency potential } \\
(£ / \text { annum) }\end{array}$ & $\begin{array}{l}\text { Proportion of annual energy } \\
\text { bills (\%) }\end{array}$ \\
\hline Fishmonger & $£ 10000$ & $£ 1380$ & $14 \%$ \\
\hline Butcher & $£ 8400$ & $£ 4800$ & $57 \%$ \\
\hline Cycle-shop & $£ 1770$ & $£ 770$ & $44 \%$ \\
\hline
\end{tabular}

alt-text: Table 2

Table 2

(i) The presentation of Tables and the formatting of text in the online proof do not match the final output, though the data is the same. To preview the actual presentation, view the Proof. 


\begin{tabular}{|c|c|c|c|}
\hline Retailer & Butcher $\underline{\operatorname{shop}}^{a}$ & Fishmonger ${ }^{5} \underline{\text { Fishmonger }}^{b}$ & Cycle-shop \\
\hline Energy & Electricity only & Electricity and gas & Electricity (gas present, but not used) \\
\hline $\begin{array}{l}\text { Energy } \\
\text { intensity } \\
\left(\mathrm{kWh} / \mathrm{m}^{2}\right. \\
\text { total } \\
\text { floor } \\
\text { area) }\end{array}$ & 410 & 740 & 90 \\
\hline $\begin{array}{l}\text { Heating / } \\
\text { cooling }\end{array}$ & $\begin{array}{l}\text { Premises unheated. Air- } \\
\text { conditioner }(5 \mathrm{~kW}) \text { used for } \\
\text { cooling in summer, with } \\
\text { manual controls installed in } \\
1980 \mathrm{~s} \text {. }\end{array}$ & $\begin{array}{l}\text { Shop floor unheated/cooled. Back } \\
\text { office/staff room heated in winter } \\
\text { (programmable thermostat). } \\
\text { Condensing combi boiler provides } \\
\text { heating/hot water. }\end{array}$ & $\begin{array}{l}\text { Gas boiler had broken two years } \\
\text { previously. Replaced with } 10 \mathrm{~kW} \text { air } \\
\text { conditioner to provide heating and } \\
\text { cooling, as shop over-heats in summer } \\
\text { (south facing shop window). }\end{array}$ \\
\hline $\begin{array}{l}\text { Major } \\
\text { other } \\
\text { energy } \\
\text { uses }\end{array}$ & $\begin{array}{l}\text { Refrigeration (all }>20 \text { years } \\
\text { old) included } 12 \mathrm{~m}^{2} \text { freezer- } \\
\text { room, } 12 \mathrm{~m}^{2} \text { chiller-room } \\
\text { operated } 24 / 7 \text {. Approx. } 12 \mathrm{~m}^{2} \\
\text { of shop floor chilled displays, } \\
\text { operated when occupied. } \\
\text { Lighting included fluorescent } \\
\text { T8 tubes, LED and halogen } \\
\text { downlighters. }\end{array}$ & $\begin{array}{l}\text { Refrigeration included } 5 \mathrm{~m}^{2} \text { freezer } \\
\text { room and } 3 \times 4 \mathrm{~m}^{2} \text { chiller rooms and } \\
6 \mathrm{x} \text { freezer units operated } 24 / 7 \text {. } \\
4 \times 2 \mathrm{~m}^{2} \text { fish displays (crushed ice } \\
\text { bed) used during operating hours. } \\
\text { Lighting included fluorescent } \mathrm{T} 8 \\
\text { tubes and LED downlighters on when } \\
\text { occupied (some turned off when } \\
\text { bright). }\end{array}$ & $\begin{array}{l}\text { Lighting included } 22 \times 70 \mathrm{w} \text { metal-halide } \\
\text { downlighters (narrow and deep shop } \\
\text { floor and lack of natural lighting } \\
\text { requires bright lighting products), LED } \\
\text { T8 tubes in basement and LED } \\
\text { spotlights in office (all used when } \\
\text { occupied). Other equipment included } \\
\text { ICT (Computers, server and small } \\
\text { power). }\end{array}$ \\
\hline
\end{tabular}

\section{Table Footnotes}

${ }^{a}$ Note, the cycle-shop was not able to produce an annual energy bill estimate, so the estimate is based on a bottom up assessment only.

$\mathrm{b}_{6 \%} \%$ of the fishmonger's energy use was unaccounted for, which may be down to the participant's reluctance to show the researcher around the back-office areas.

alt-text: Table 3

Table 3

(i) The presentation of Tables and the formatting of text in the online proof do not match the final output, though the data is the same. To preview the actual presentation, view the Proof.

Example energy efficiency opportunities presented to retailers (fishmonger).

\begin{tabular}{|c|c|c|c|c|c|c|c|}
\hline $\begin{array}{l}\text { Location/opportunity } \\
\text { type }\end{array}$ & $\begin{array}{l}\text { Current } \\
\text { equipment }\end{array}$ & $\begin{array}{l}\text { Current } \\
\text { annual } \\
\text { energy } \\
\text { cost }\end{array}$ & $\begin{array}{l}\text { Proposed } \\
\text { action }\end{array}$ & $\begin{array}{l}\text { New } \\
\text { annual } \\
\text { energy } \\
\text { cost }\end{array}$ & $\begin{array}{l}\text { Replacement } \\
\text { cost ( } £ \text { Inc } \\
\text { VAT) }\end{array}$ & $\begin{array}{l}\text { Estimated } \\
\text { annual } \\
\text { energy } \\
\text { savings }\end{array}$ & $\begin{array}{l}\text { Investment } \\
\text { break even } \\
\text { (years) }\end{array}$ \\
\hline Shop-floor lighting & Strip lighting: & $£ 700$ & $28 \times 4 \mathrm{ft}$ T8 LED & $£ 220$ & $£ 250$ & $£ 480$ & $0.5(6$ \\
\hline
\end{tabular}




\begin{tabular}{|c|c|c|c|c|c|c|c|}
\hline & $\begin{array}{l}28 \times 4 \mathrm{ft} \mathrm{T} 8 \\
\text { Fluorescent } \\
\text { tubes }(58 \mathrm{w})\end{array}$ & (approx.) & $\begin{array}{l}\text { replacement } \\
\text { tubes ( } 22 \mathrm{w} \\
\text { equivalent) }\end{array}$ & (approx.) & (approx.) & (approx.) & months) \\
\hline Shop-floor & $\begin{array}{l}\text { Fish display } \\
\text { counters }(\mathrm{x} 2, \\
2.95 \mathrm{~m} \times 1 \mathrm{~m})\end{array}$ & $\begin{array}{l}£ 2200 \\
\text { (approx.) }\end{array}$ & $\begin{array}{l}\text { Retrofit glass } \\
\text { door/lid }\end{array}$ & $\begin{array}{l}£ 1350 \\
\text { (approx.) }\end{array}$ & N/A & $\begin{array}{l}£ 850 \\
\text { (approx.) }\end{array}$ & N/A \\
\hline Shop-floor & $\begin{array}{l}\text { 2x display } \\
\text { freezers } \\
\text { located under } \\
\text { awning }\end{array}$ & $\begin{array}{l}£ 550 \\
\text { (approx.) }\end{array}$ & $\begin{array}{l}\text { Move both } \\
\text { displays to back } \\
\text { of shop }\end{array}$ & $£ 500$ & $£ 0$ & $\begin{array}{l}£ 50 \\
\text { (approx.) }\end{array}$ & N/A \\
\hline
\end{tabular}

The next sections summarise analysis of the findings based on the adapted 4Cs framework.

\subsection{Concern}

The first $\mathrm{C}$ is Concern, which includes factors which shape attention to energy use. These could be influenced by a range of issues including reputational concern (e.g. from customers), internal or external business contexts (e.g. staff related issues, regulatory influences) or operational factors (e.g. energy costs). It was found that, for these cases, two issues; internal business contexts and costs, were most salient.

\subsubsection{Internal business contexts}

Internal business contexts appeared to play a key role in the types of energy efficiency measures of interest and likelihood to act. As described above, the cycle-shop owner and fishmonger were mid-career and planning to continue in the business long-term. As such, both were making 'strategic' investments in their businesses over time. For example, both had replaced expensive energy-using equipment and/or upgraded the shop in recent years and were planning further activities in future principally influenced by commercial influences, which are discussed below. By contrast, the semi-retired butcher had not replaced any equipment for over a decade and was 'making-do' while planning to sell the business to a new owner. These contexts appeared to very strongly influence the types of energy efficiency measures considered. For example, whereas large-scale equipment upgrades were considered by the fishmonger and cycle-shop, the butcher was not interested in any measures which involved significant financial outlay "I'm semi-retired now, and I don't have the energy for such endeavours - I'll leave that to whoever takes over" (Butcher).

\subsubsection{Costs: investments vs. operational costs}

All three retailers suggested that in the current, challenging retail climate, profits were marginal and costs high, meaning that operational-savings were of keen interest. For example, while the butcher was not interested in investing in the business, he had a keen interest in low-cost actions which would deliver operational savings. An opportunity of key interest was rationalisation of space in the freezer-room [45], which could be done by splitting the room in two by inserting an insulated wall and door between the two motors (Fig. 3). This was perceived favourably as it would both save costs and provide additional benefits such as greater storage flexibility. "It's an interesting idea as it wouldn't cost much, and in normal business we never use all the space 
- that's only at Christmas time"..."It would also mean we have a back-up in place in case one of the motors breaks down" (Butcher).[Instruction: Fig 3 (picture of cold room motors) should be placed here]

By contrast, the fishmonger seemed less interested in this type of opportunity despite there being potential for it and was more interested in investing in upgrading equipment on the shop-floor, on the basis that these also had potential commercial benefits. As described further below, if measures had a commercial influence on the business, then capital costs and payback appeared to play much less of a role, than other issues such as customer experience (see conditions section, below for further details). [Instruction: Figure 4 should be placed here (Electricity meters Butcher picture)]

Concern over energy costs and related investment in energy efficiency measures was less salient for the cycleshop owner, who could not estimate bills and, in fact, had not been billed for nearly a year, due to an issue arising when switching suppliers (stating that despite making efforts on several occasions to rectify the situation the supplier still hadn't set up their bills). In contrast, the fishmonger and butcher who had higher bills had made efforts to understand them and reduce demand. "Yeah, it makes sense [referring to estimated energyuse Table 2[Instruction: As above, please update this table reference to refer to the three pie charts figure]] but I could have told you that, I pretty much know what uses what!"..."Our supply is three-phase and [we] have three meters, the electrician showed me one spins faster than the others"..." I know that one is hooked up to the cold-room as it stops when the fuse goes" (Butcher, Fig. 4).

\subsection{Conditions}

The second $\mathrm{C}$ is Conditions; factors which shape where energy actions occur, and include all the energy efficiency opportunities described by abatement studies, such as the BEES survey [15]. Many opportunities of all types (monitoring, behaviour, equipment replacement/maintenance, refurbishment) were found in all premises (Table 1, Fig. 5), reflecting previously described low energy efficiency take-up among SMEs [22]. Whilst all the retailers were leaseholders, they claimed responsibility for a wide range of equipment and fabric, asserting that landlords tended to only be responsible for fundamental structural fabric ${ }_{-}^{4}$ Lease lengths appeared to play some role in investment decision-making, although all three had long leases left to run, which limited potential for exploring such issues in depth. Responses to conditions were influenced by other 'Cs' for example, while the butcher had high technical energy efficiency potential from equipment upgrades, they were in effect made redundant by internal business context, as the butcher was planning retirement. [Instruction: Figure 5 needs to be placed here (pictures of butcher refridgeration equipment and chest freezer displays). It is fine to rearrange them so they are placed vertically as opposed to horizontally if that helps]

\subsubsection{Time and trigger points}

As described above, one of the limitations of the 4Cs framework, [34] is that it represents a snapshot in time, so does not consider that responses to available opportunities may change over time. Discussion of opportunities with participants identified potential 'trigger-points', which were likely to instigate action, a phenomenon which has been previously described in the domestic sector [20]. Several potential triggers were linked to energy management (e.g. billing/contracting, equipment maintenance/replacement, shop fit-out), which supports arguments suggesting that these could be useful points at which to explore policy interventions 
[30]. However, some triggers appeared to be more influential than others. For example, energy billing/contracting appeared to be limited by interaction with a less-trusted supply chain actor (energy suppliers, and/or third party intermediaries, such as energy brokers ${ }^{5}$ ) and lack of a timely link to physical changes undertaken on site, which are often needed for energy efficiency adoption (e.g. refurbishment). While less frequently occurring, equipment maintenance/ replacement involved making physical changes, and those involved (electricians, equipment engineers) were perceived to be more likely to be able to ascertain key information regarding energy use, which could inform tailored energy efficiency advice, albeit it was recognised by participants that this was not currently something they tended to do. Some trigger points, such as shop fit-outs occurred infrequently (every 10--20 years), but appeared to be potentially very influential, as both key equipment (e.g. refrigeration) and fabric (e.g. shop-fronts, glazing and insulation) would be upgraded at these points.

\subsubsection{Commercial influences}

Of all conditions influencing consideration of energy efficiency measures, commercial influences appeared the most important. As described above, the main commercial opportunity open to the retailers was perceived to be attracting customers to 'walk-in' off the street. The majority of energy use was dedicated to shop floor activities, which were focused on enhancing customers' experience and thereby sales; for example, by providing a welcoming, attractive shop environment, with appealingly displayed, easy to access produce. All three retailers described considerable efforts they went to, continually investing time and money in getting conditions 'right' for their premises and the implications this had for energy services. An example which demonstrates the importance of these commercial influences was found in the strategies employed regarding heating and cooling. Both the butcher and fishmonger did not heat their premises during winter. This meant they dressed for the cold in winter, and staff in both shops complained of cold hands and feet as a key problem. There were several reasons for this; first, it helped enable them to keep the front door open more often, ${ }_{2}^{6}$ which was widely perceived to benefit trade; second, whilst they recognised that the shop was therefore also cold for customers, they perceived that customers 'expect' the shop to be cool as it helps keep displayed produce fresh; third, customers are dressed for the cold as they come in from outside. In this context, whilst winter could be uncomfortable for staff, customer expectations over-rode this. For energy efficiency, this likely means that heating measures are less of an opportunity here than in other sectors. However, by contrast in summer, space cooling may need more consideration, as for similar reasons, the butcher also actively cooled the space in summer.

\subsubsection{Responses to energy efficiency opportunities}

Considering the contexts set out above, many energy efficiency measures were perceived as highly disruptive, so retailers expressed strong views on a range of opportunities discussed. For example, all three retailers agreed that energy efficient lighting was an opportunity for energy saving. The financial savings and paybacks ( $<6$ months) were all seen as attractive and worth the outlay/hassle of implementation. However, several social and technical issues were also discussed. "They must be as bright or brighter than the current ones, and the right colour [of light]"... "It's also got to not leave dark shadows - that was, and still is a major issue when we got these [pointing to their current display lighting]" (Cycle-shop). Linked to commercial influences discussed 
above, all noted the importance of light quality, including colour and brightness, to 'show-off' the displays, without glare and minimising shadows. Considerable efforts had been invested in getting the lighting 'right' from an aesthetic perspective, which led some to be wary of changes on the basis of risk that it wouldn't achieve the same effect as had been (painstakingly for some) achieved with the current set-up. Whilst the, relatively higher, capital cost of LED lighting was noted as a potential barrier (for those who didn't already have it), this appeared to be outweighed by these concerns. These findings contrast some of the literature, where lighting is seen as 'low hanging fruit' [15].

Refrigeration opportunities, which comprised the vast majority of energy use for the butcher and fishmonger were similarly influenced. For example, it was suggested that the fishmonger rearrange the space to move the under-awning chest freezers towards the back of the shop, particularly in hot weather as a 'no-cost' measure to reduce energy demand. Apparently, this had been tried previously, but they found it negatively affected sales from the freezers when they were there.[Instruction: Fig 6 needs to be placed here (under-awning chest display freezer (Fishmonger)]

"I have tried lots of different arrangements for the shop and now I wouldn't move the freezers from here"... "What I find is that people browse under the awning while they are waiting to be served from the fresh fish counter. By having the freezers here, I sell maybe 60 bags of frozen prawns a week!" (Fishmonger).

Finally, the suggestion of adding glass lids/covers to refrigerated display cabinets to reduce energy use (Fig. 7) was strongly rejected for both commercial and operational reasons.

"On a Saturday, we go into that display maybe 700 times per day, so it would be open and shut, open and shut all the time, which would annoy the staff. Also, we'd get fish muck on the glass each time which would put customers off!" (Fishmonger).[Instruction: Fig 7 should be placed here (Picture of crushed ice displays)]

\subsection{Capacity}

Capacity within the 4Cs framework is described as factors that moderate abilities to take energy actions, which have been interpreted here to include internal resources and capital costs. As described above, these have been described as key barriers for SME energy efficiency adoption previously [15,22] and they were also found here. Interestingly however, for the retailers, which were generally less structured than larger organisations, capacity appeared to have a relatively fluid meaning, and influences between Capacity and Concern were apparent. If an issue was of key strategic concern, such as a commercial influence, resources would be made available, but if not, they were not. For example, for the fishmonger, the crushed-ice displays were perceived as crucial to attracting customers "I just spent ten grand [£10,000] upgrading these ones (pointing to the crushed-iced displays", (see-Fig. 7). By contrast, their back-room storage chest freezers were old and inefficient. However, these were not visible to customers, and there appeared to be little appetite for upgrading them.

\subsection{Communities}


The Communities aspect of 4Cs considers different analytical layers used in socio-technical energy efficiency adoption studies, including (but not limited to) organisational and individual (i.e. employees) frames. As described above, for the purposes of this study, the 4Cs framework has been collapsed here, appropriate for independent retailers as in many cases the business owner (who represents the organisation) and the employee are the same person. Notwithstanding that, 'grey' areas still exist and there were notable external influences, in particular that of "middle actors' ${ }^{7}[31,47]$, which is discussed below. Independent retailers may have a lot of control over their business, but they exist in an economic ecosystem. We adapt the notion of "community" here to include professional service providers; particularly shopfitters, electricians and equipment engineers, viewing them as middle actors in the economic ecosystem in which independent retailers operate.

\subsubsection{Middle actors}

While the retailers appeared to have some understanding of energy use and how their business activities related to it, they did not profess to be experts, and relied on an existing network of middle actors to help them when needed. The most trusted and seemingly influential actors included electricians and to a slightly lesser extent equipment engineers "If I were to do it [replace shop-floor lighting], I'd get [Electrician's name] in as he'd know what I needed" (Butcher). All participants had long-established, trusted relationships with electricians who undertook general wiring and basic equipment servicing including portable appliance testing (PAT). Trust appeared to be linked to electricians' independence from specific energy using equipment, and time spent on-site, which appeared to influence relationship building. Interestingly the fishmonger identified PAT testing as a useful opportunity to provide advice on electricity use as he had previously had discussions about equipment at that time. "My PAT-tester tells me how much juice [electricity] the cold-room is drawing, as well as the chillers and freezers"..."He's already told me that-that the small freezer is drawing more power than the chest-freezer. I'll be replacing that one first." (Fishmonger). Energy suppliers (sometimes via third party intermediaries) were also involved, but less trusted, due to perceptions of vested interests. Finally, shopfitters were also perceived to be important, although exploration was limited as only one retailer had _[Instruction: Here I think we do need to have two 'hads'.] had had a recent refurbishment undertaken. These actors would clearly be closely involved in energy efficiency adoption and could represent useful routes through which to deliver policy interventions, such as information and advice provision (albeit currently there is little knowledge about the supply chain's skills and capacity for this).

\subsection{Cs for independent retail: an energy efficiency adoption framework}

The findings from this research have informed the development of an energy efficiency adoption framework for independent retailers, building on Janda's 4Cs framework, shown in Fig. 8. The figure is a development on Fig. 1, providing additional granularity regarding key issues influencing each $\mathrm{C}$ and how they manifest themselves for each retailer using example energy efficiency opportunities explored with them.[Instruction: Figure 8 should be placed here.]

alt-text: Fig 1

Fig. 1 


\begin{tabular}{|c|c|c|c|c|}
\hline & \multirow[b]{2}{*}{$\begin{array}{l}\text { Anslytikal } \\
\text { lewel }\end{array}$} & \multicolumn{3}{|c|}{30} \\
\hline & & $\begin{array}{l}\text { Concern (fatars } \\
\text { that shape } \\
\text { attention to } \\
\text { energy) }\end{array}$ & $\begin{array}{l}\text { Condtions (faxtors that shape } \\
\text { where mergy actions acaur) }\end{array}$ & $\begin{array}{l}\text { Capadity (factors that moderate } \\
\text { wilities to take energ actions) }\end{array}$ \\
\hline \multirow{3}{*}{$\begin{array}{l}\text { Bullding communities } \\
\text { (grey ame, neither } \\
\text { ofganbasonal nor } \\
\text { individual) }\end{array}$} & Organizatibe & $\begin{array}{l}\text { lepslative } \\
\text { mquirements, } \\
\text { kases }\end{array}$ & $\begin{array}{l}\text { Builing retrofit opportunibes themostat } \\
\text { setpoints, standrd operabional hous, } \\
\text { provisibe of space s equipment }\end{array}$ & 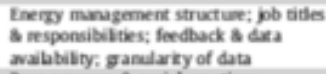 \\
\hline & & Worksityles & 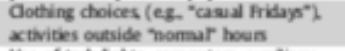 & $\begin{array}{l}\text { Ner pressuer \& social practices; } \\
\text { workgoup đynamia }\end{array}$ \\
\hline & Individual & $\begin{array}{l}\text { Nerisudes, betiefs, } \\
\text { habies, values }\end{array}$ & $\begin{array}{l}\text { Uhe of task lighes, computers, auxilary } \\
\text { herting/cooling devices extra plug bads; } \\
\text { operation of binds/windows }\end{array}$ & 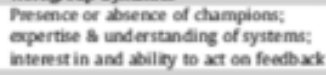 \\
\hline
\end{tabular}

4Cs framework: concern, capacity, conditions within a community Source: [7][34].[Instruction: Fig 1 needs to be placed in section 2.2 - I have put a comment where it ought to be]

\section{Replacement Image: 4Cs table.docx}

Replacement Instruction: This is the original word document table which was used in the Janda 2014 paper. Could you please use this, but format it so that it looks like the previous image (which was a low-res version of the formatted table, which appears in the 2014 Janda paper.

\section{alt-text: Fig 2}

\section{Fig. 2}

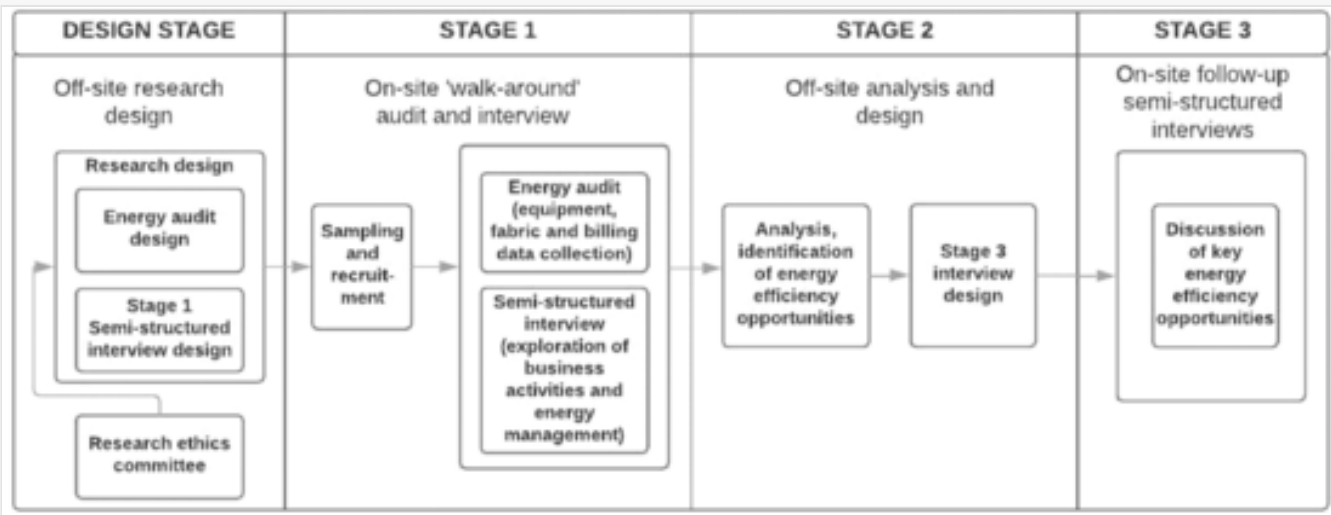

Staged research design overview.[Instruction: Fig 2 needs to be moved to section 3 - I have put a comment where it needs to be]

Considering this and previous work on the framework, each of the 4Cs appear necessary, but their presence is not necessarily sufficient for action to be taken. Some Cs (e.g. Concern) are more important than others. Conditions, and in particular the presence of energy efficiency opportunities within Conditions, appears to be of less importance than other influences. Capacity is of variable importance, and is strongly influenced by the other Cs.

Each of the Cs have 'sub-components' or factors, which have variable influence. For example, within Concern, internal business contexts appeared to strongly outweigh concerns driven by operational costs. Social and 
environmental concerns, which appear to influence larger organisations (e.g., fostering corporate social responsibility activities [4] appeared to have little to no influence at the time of undertaking the research.

The 4th C (Communities), plays a strong role across all aspects of the other Cs as middle actors are heavily relied upon and very important influencers in the context of energy use. Within this, electricians and equipment engineers appear to have most influencing potential on the basis that according to participants they understand key issues such as business contexts and commercial influences and are trusted actors who would likely be turned to first when considering taking action.

The C's and in particular their sub-components interrelate, for example business contexts that create Concern and commercial factors that affect Conditions influence each other and together likely represent the most important elements in influencing action.

Finally, the C's and factors within them may change over time, influenced by a range of trigger points, which are occur more or less frequently and have differing levels of influence.

\section{Discussion}

Considering social and technical issues together as has been undertaken here, whilst challenging from a methods perspective, demonstrates the value of such work and richness of insights that it can bring. If these issues were considered separately, and / or in isolation, a quite different picture of the opportunities and challenges associated with increasing energy efficiency adoption within the sector would likely emerge. Using a staged research design helped overcome some inherent challenges associated with this type of approach. For example, it facilitated an open, exploratory approach to energy efficiency adoption to be taken in the early stages, enabling key issues such as concerns arising from internal business contexts to be considered. This resulted in a more appropriately targeted exploration of energy efficiency opportunities later in the research. Simply recommending measures which represented the largest and/or quickest paying back opportunities (e.g., the techno-economic features commonly associated with physical conditions), as is common with energy efficiency research, would ignore critical components of the actual adoption criteria and likely result in higher levels of rejection [33]. Several, seemingly obvious opportunities were quickly ruled out on the basis that they did not 'fit' with business needs or did not take account of underlying contexts explored in stage 1 fieldwork. Furthermore, demonstrating that these specific concerns and organisational capacities had influenced the recommended energy efficiency opportunities explored in stage 3, appeared to help engagement and interest from retailers during the follow up research. Notwithstanding this, the approach was resource intensive, and striking a sensible balance between efforts expended on quantitative and qualitative approaches was challenging.

\section{Conclusions and recommendations}

Lack of research to investigate energy efficiency potential in small businesses and recent developments in socio-technical methods inspired the first author to apply case study mixed-methods to explore energy efficiency adoption in independent retail, using an existing 4Cs framework (concern, conditions, capacity and communities) [34]. This paper has demonstrated how social and technical issues can be explored together, and 
in so doing overcome limitations of traditional social or technical research in informing policy. Based on the empirical evidence, the 4Cs framework has been augmented, through the inclusion the likely differences in importance of different Cs, and the inclusion of trigger points, to inform a conceptual framework for energy efficiency adoption for independent retail (Fig. 8). However, further empirical work will need to be carried out to test the usefulness of this new framework. However, in the meantime, the following developments on the $4 \mathrm{Cs}$, relevant for independent retail are suggested.

By using the approach taken here, it is possible to add further granularity to the framework, for example identifying interrelationships between $\mathrm{Cs}$ and underlying factors which appear most important in determining responses to energy efficiency opportunities. For example, some Cs can 'trump' others, driven by some of the underlying factors within them (e.g. internal business contexts - within Concern; commercial influences within Conditions). Finally, it is also possible to identify and explore time and 'trigger points' and identify possible routes for policy intervention (e.g. working through middle-actors). Some of the abovementioned findings may be sector specific, but they could also be transferable to other parts of the non-domestic sector. For example, identified commercial influences would likely be prevalent across other parts of the-retail-sector, hospitality and other 'business-to-consumer' sectors. Furthermore, some of the identified internal business contexts could be prevalent to many other SMEs with similar ownership profiles.

Reflecting on the 4Cs, improving energy efficiency within this sector is clearly complex, so it is perhaps not surprising that energy efficiency adoption has been low in this sector to date. However, this research highlights the importance of social contexts in influencing action. For example, this research clearly suggests that physical conditions (i.e. the presence of energy efficiency opportunities), whilst the most important factor in engineering calculations of technical potential, appears to be of much less importance than the other Cs (concern, capacity, communities) in reality. This suggests that further work to explore non-technical factors would be valuable in helping to inform effective policy interventions.

Finally, commercial influences on energy services, play a very significant role and retailers have considerable expertise and skills in understanding these. Energy efficiency opportunities are highly disruptive within this context, in ways which are poorly understood and require further investigation. This provides both opportunities and constraints for policy intervention and whilst the findings are mainly limited to independent retail, the issues explored may be transferable to a range of other customer-facing organisations.

\subsection{Recommendations for policy}

The findings suggest that energy efficiency interventions should be designed to take account of both social and technical aspects of the 4Cs and the issues which lie within each. The observed interrelationships between them means that lack of consideration of one or more of them could result in missing key influences which could limit take up of energy efficient technologies and strategies.

There are a range of policy considerations emanating from this work. Considering how context-specific energy efficiency potential appears to be, it stands to reason that policies which are derived from and prioritise technical opportunities (e.g. energy efficiency audits) are likely to be very challenging to get traction without clear and explicit consideration of the other social contexts. Considering the findings of this, and related work 
$[7,28,31]$ suggests that policy should focus on better understanding organisations and the people who work in and for them first before considering what technical opportunities might be suitable. This appears to be the opposite of what occurs in practice, and suggests that much more work is needed to better understand 'social potential' [34] of SMEs.

However, the research also identifies some interesting opportunities. First, there appears to be a range of trusted middle actors (electricians, equipment engineers and likely also shop-fitters), who appear to already have very good understanding of business contexts and commercial influences of these sectors and represent interesting opportunities for policy intervention. Secondly, the finding that the shop-keepers, armed with only limited information about their energy use, were able to suggest appropriate energy efficiency opportunities themselves, suggests that innovation with instruments such as smart meters are worthy of closer investigation.

\subsection{Recommendations for future research}

The energy efficiency adoption conceptual framework presented here is descriptive and further work is required to hone it and make it more useful to inform policy. As described above, investigating further the interrelationships between each $\mathrm{C}$ and the identified underlying factors may help to further inform the framework. It would be beneficial to broaden the scope of future research to include middle actors for small retailers and the supply chain for each business type. Each of these groups may offer additional 'routes' for effective policy implementation. It would also be informative to conduct research with retailers identified as being at key 'trigger points' to further investigate the potential for intervention at these points. Finally, it would be useful to conduct similar research among other energy intensive non-domestic sectors, as this would help understand how issues differ across sectors, which would improve the transferability of these findings to other parts of the sector. Finally, as described above, studies to further investigate interventions informed by smart meters would be useful. Given the current lack of understanding of interventions and the contexts within which they may be effective, action research studies are likely to be helpful.

Figs. 3, 4.[Instruction: Fig 3 needs to be moved to section 4.2.2 (I have placed a comment in that section where it needs to go)]

alt-text: Fig 3

Fig. 3 


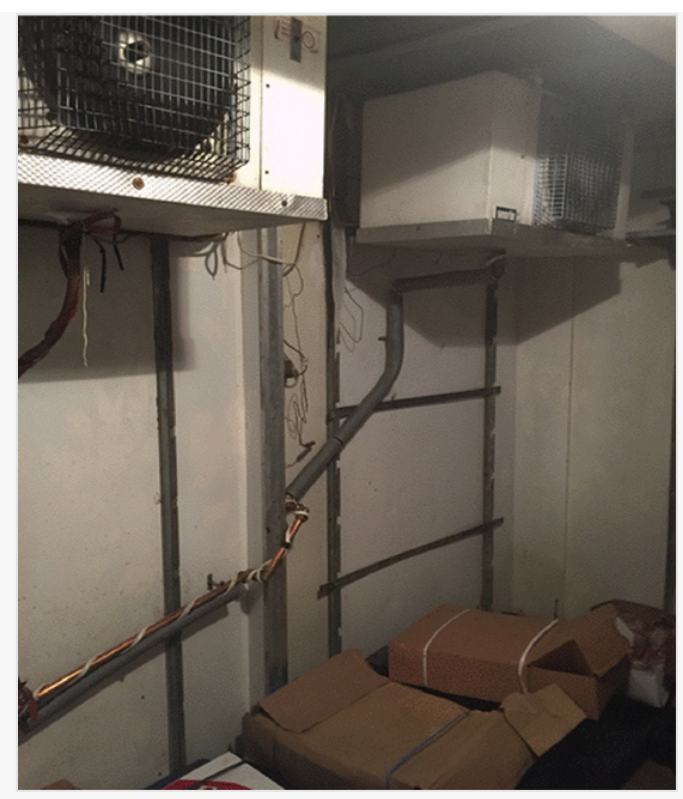

Butcher cold room motors.

alt-text: Fig 4

Fig. 4

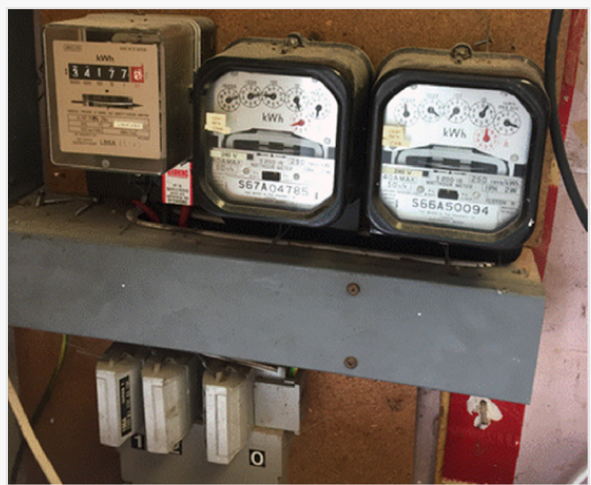

Electricity meters (Butcher).

alt-text: Fig 5

Fig. 5 

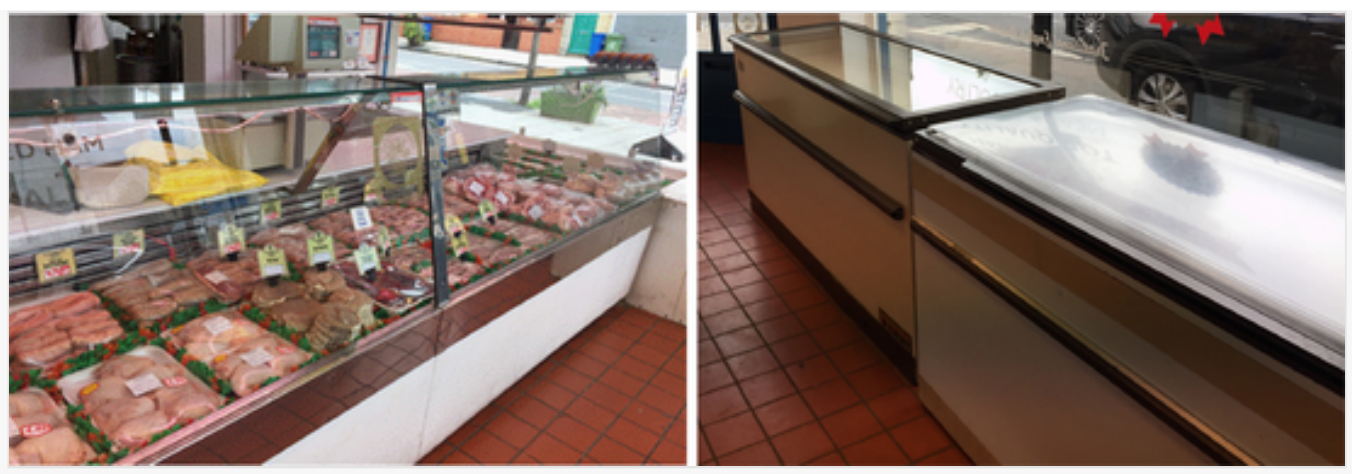

Butcher refrigeration equipment including over-counter and chest freezer displays (all over 20 years of age). [Instruction: Figure 5 needs to move to section 4.3 - I have put a comment in that section where it ought to go]

alt-text: Fig 6

Fig. 6

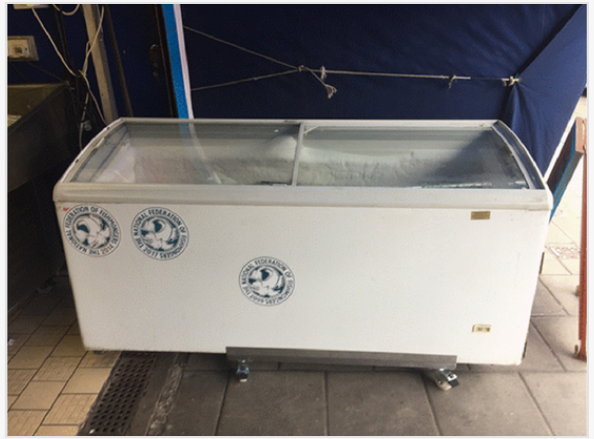

Under-awning chest display freezer (Fishmonger).

alt-text: Fig 7

Fig. 7

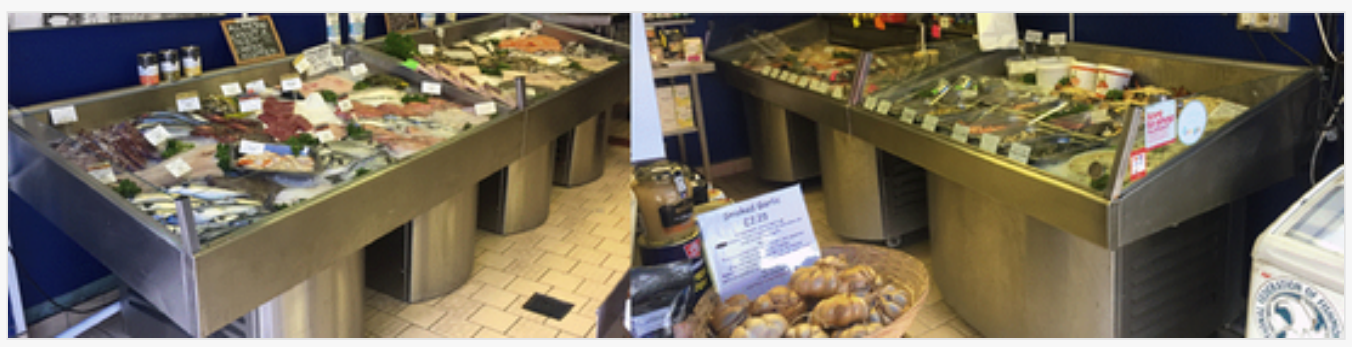

Crushed ice fish displays (Fishmonger). [Instruction: Fig 7 needs to be moved to section 4.3.3 - have put a comment to show where it should be]

alt-text: Fig 8 
Figure Replacement Requested

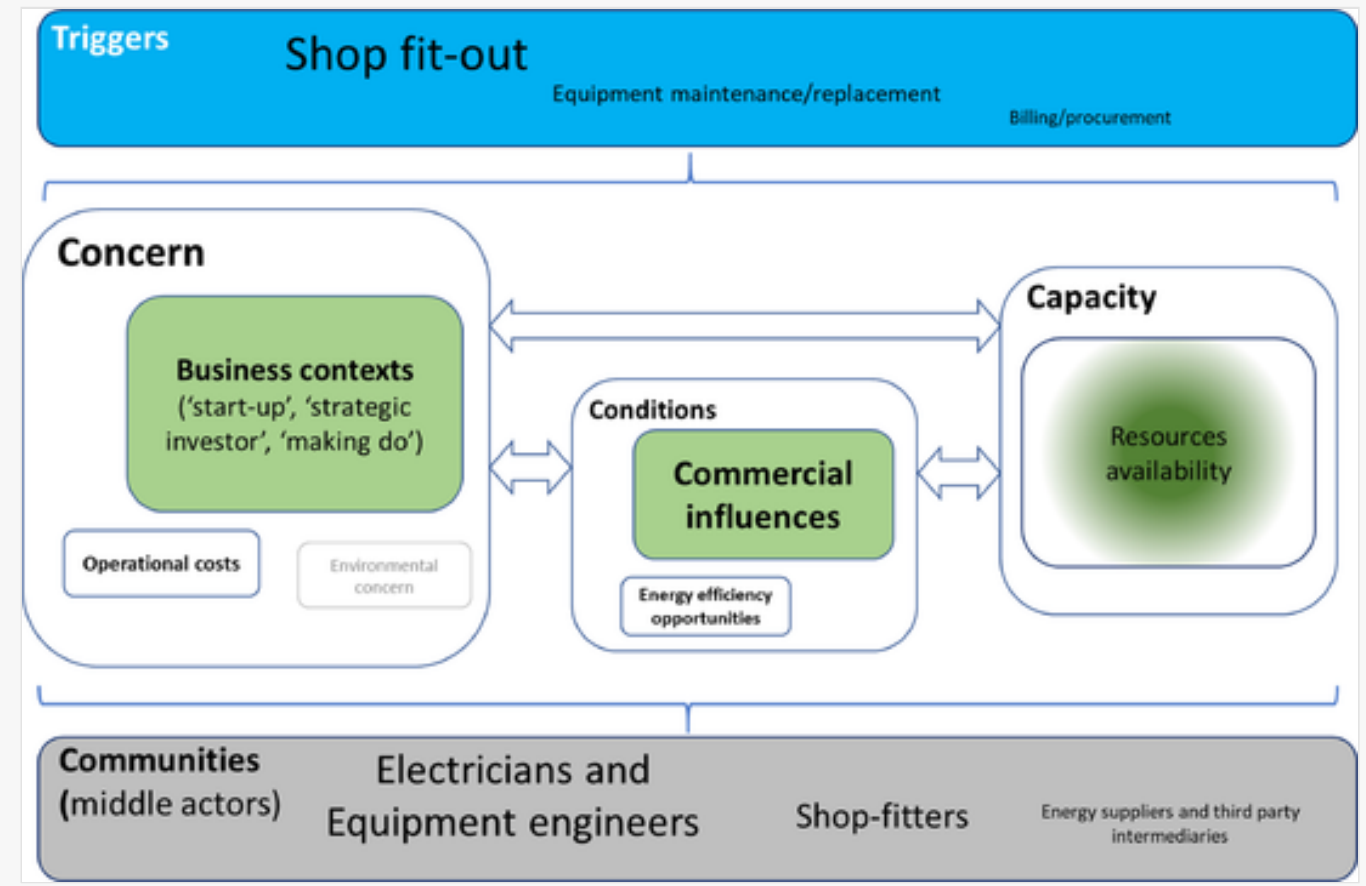

[Instruction: Fig 8 should be placed in section 4.6 - I have put a comment in the place it should be.]4Cs for independent retail.

\section{Replacement Image: 4Cs for independent retail.pptx}

Replacement Instruction: I have edited this some more and attached the document I made it in to make it look a bit better. However, if you can help make it look better, it would be gratefully received! For example, the corners of the boxes could be made to be sharper, and the colours may not be the best. Apologies, my editing skills are somewhat rudimentary!

\section{Declaration of interests}

The authors declare that they have no known competing financial interests or personal relationships that could have appeared to influence the work reported in this paper.

\section{Disclosure statement}

No potential conflict of interest was reported by the author.

\section{Funding}

This work was supported by the Engineering and Physical Sciences Research Council (EPSRC)_Centre for Doctoral Training in Energy Demand (LoLo) under Grant numbers EP/L01517X/1 andEP/H009612/1.

\section{References}


[1] S.T. Anderson, R.G. Newell, Information programs for technology adoption: the case of energyefficiency audits, Resource and Energy Economics $26 \quad$ (2004) 27-50, doi:10.1016/j.reseneeco.2003.07.001.

[2] N. Banks, T. Fawcett, Z. Redgrove, What are the factors influencing energy behaviours and decision-making in the non-domestic sector?, A Rapid Evidence Assessment (2012) DOI:

[3] N.W. Biggart, L. Lutzenhiser, Economic sociology and the social problem of energy inefficiency, American Behavioral Scientist 50 (2007) 1070-1087, doi:10.1177/0002764207299355.

[4] J.C. Borck, C. Coglianese, Voluntary environmental programs: Assessing their effectiveness, Annu. Rev. Environ. Resour. 34 (2009) 305-324, doi:10.1146/annurev.environ.032908.091450.

[5] J.S. Broc, C. Cooremans, What did we recently learn about the evaluation of energy efficiency policies and programmes? insights from ieppec 2014 in berlin, Energy Efficiency 9 (2016) 843846, doi:10.1007/s12053-016-9457-4.

[6] H. Bruhns, P. Wyatt, A data framework for measuring the energy consumption of the nondomestic building stock, Building Research \& Information 39 (2011) 211-226, doi:10.1080/09613218.2011.559704.

[7] R.Bull BultR., K.B.Janda Janda, Beyond feedback: introducing the 'engagement gap' in organizational energy management, Building Research \& Information[Instruction: KJ comment: Bull \& Janda is 2018 in print, was 2017 online. Print version is probably better to cite.] 46 (z0172018) 300-315, doi:10.1080/09613218.2017.1366748.

[8] J. Cauvain, A. Karvonen, Social housing providers as unlikely low-carbon innovators, Energy Build 177 (2018) 394-401. https://doi.org/10.1016/j.enbuild.2018.08.012.

[9] K. Charmaz, Constructionism and the ground theory, Handbook of Constructionist Research, The Guildford Press, New York, 2008.

[10] Chartered Institution of Building Services Engineers, Energy Assessment and Reporting Method, 2006 CIBSE TM22 [Online].

[11] L.F. Chiu, R. Lowe, R. Raslan, H. Altamirano-Medina, J. Wingfield, A socio-technical approach to post-occupancy evaluation: interactive adaptability in domestic retrofit, Build. Res. Inf. 42 (2014) 574-590, doi:10.1080/09613218.2014.912539.

[12] C. Advice, Smart[Instruction: As per comment on p2 - this should be Citizens Advice, not C. Advice as currently shown.] choices: Investigating microbusinesses' Interest in, and 
Understanding of, Smart Meters, 2017 [Online]. Available:. https://www.citizensadvice.org.uk/G1 obal/CitizensAdvice/Energy/Smart\%20microbusiness\%20report\%20(1).pdf.

[13] R.J. Cole, Motivating stakeholders to deliver environmental change, Build. Res. Inf. 39 (2011) 431-435, doi:10.1080/09613218.2011.599057.

[14] C. Cooremans, Investment in energy efficiency: do the characteristics of investments matter, Energy Efficiency 5 (2012) 497-518, doi:10.1007/s12053-012-9154-x.

[15] Department of Business Energy and Industrial Strategy, Building Energy Efficiency Survey (BEES), 2016 [Online]. Available:. https://www.gov.uk/government/collections/non-domestic-bu ildings-energy-use-project.

[16] Department of Business Energy and Industrial Strategy, The Energy Technology List \& Enhanced Capital Allowances scheme: A guide to Saving Energy and Costs Through the Purchase of High Performance Energy Efficient Equipment, 2018 [Online]. Available:. https://ass ets.publishing.service.gov.uk/government/uploads/system/uploads/attachment_data/file/686856/E CA272 February_2018.pdf.

[17] Department of Business Energy and Industrial Strategy2019. UK becomes first major economy to pass net zero emissions law. Gov.uk website: Department of Business Energy and Industrial Strategy.

[18] P. Devine-Wright, S. Batel, O. Aas, B. Sovacool, M.C. Labelle, A. Ruud, A conceptual framework for understanding the social acceptance of energy infrastructure: Insights from energy storage, Energy Policy 107 (2017) 27-31. https://doi.org/10.1016/j.enpol.2017.04.020.

[19] H. Eckstein (Ed.), Case Study and Theory in Political Science, Case Study and Theory in Political Science, 1975.

[20] Energy Saving Trust, Trigger points: a Convenient truth. Promoting energy Efficiency in the Home, 2011 [Online]. Available:. https://www.energysavingtrust.org.uk/sites/default/files/report s/EST Trigger Points report.pdf.

[21] European Commission, Energy Efficiency Plan, 2011, 2011 [Online]. Available:. https://ec.europ a.eu/clima/sites/clima/files/strategies/2050/docs/efficiency_plan_en.pdf.

[22] T. Fleiter, J. Schleich, P. Ravivanpong, Adoption of energy-efficiency measures in SMEs-An empirical analysis based on energy audit data from germany, Energy Policy 51 (2012) 863-875, doi:10.1016/j.enpol.2012.09.041.

[23] B. Flyvbjerg, Five misunderstandings about case-study research, Qualitative Inquiry 12 (2006) 219-245, doi:10.1177/1077800405284363.

[24] G.N. Gilbert, Researching Social Life / Edited By Nigel Gilbert, SAGE, London, London, 2001. 
[25] M. Goulden, A. Spence, Caught in the middle: The role of the facilities manager in organisational energy use, Energy Policy 85 (2015) 280-287. http://dx.doi.org/10.1016/j.enpol.20 15.06.014.

[26] J. Hamilton, R. Mayne, Y. Parag, N. Bergman, Scaling up local carbon action: the role of partnerships, networks and policy, Carbon Management 5 (2014) 463-476, doi:10.1080/17583004.2015.1035515.

[27] S. Hampton, 'It's the soft stuff that's hard': investigating the role played by low carbon smalland medium-sized enterprise advisors in sustainability transitions, Local Economy 33 (2018) 384-404, doi:10.1177/0269094218778526.

[28] S. Hampton, Making sense of energy management practice: reflections on providing low carbon support to three SMEs in the uk, Energy Efficiency (2018) 1-18, doi:10.1007/s12053-018-97505 .

[29] Iea, Accelerating Energy Efficiency in Small and Medium-sized Enterprises, 2015 [Online]. Available:. https://www.iea.org/publications/freepublications/publication/SME_2015.pdf.

[30] K. Janda, C. Bottrill, R. Layberry, Learning from the "data poor": energy management in understudied organizations, Journal of Property Investment \& Finance 32 (2014) 424-442, doi:10.1108/JPIF-03-2014-0018.

[31] K. Janda, Y. Parag, A middle-out approach for improving energy performance in buildings, Build. Res. Inf. 41 (2013) 39-50, doi:10.1080/09613218.2013.743396.

[32] K. Janda, C. Payne, R. Kunkle, L. Lutzenhiser, What organizations did (and didn't) do: Three factors that shaped conservation responses to california's 2001 "crisis", Proceedings of American Council for an Energy-Efficient Economy 2002 Summer Study Energy Efficiency in Buildings, Asilomar, CA, 2002.

[33] K.B. Janda, Bounded Decision Making and Analytical Biases in Demand Side Management, 1994 [Online].

[34] K.B. Janda, Building communities and social potential: Between and beyond organizations and individuals in commercial properties, Energy Policy 67 (2014) 48-55, doi:10.1016/j.enpol.2013.08.058.

[35] K.B. Janda, G. Killip, T. Fawcett, Reducing carbon from the 'Middle-Out': The role of builders in domestic refurbishment, Buildings 4 (2014) 911-936, doi:10.3390/buildings4040911.

[36] K.B. Janda, Y. Parag, A middle-out approach for improving energy performance in buildings, Build. Res..Inf. 41 (2013) 39-50, doi:10.1080/09613218.2013.743396.

[37] J. Love, A.C.G. Cooper, From social and technical to socio-technical: Designing integrated research on domestic energy use, Indoor and Built Environment 24 (2015) 986-998, 
doi:10.1177/1420326x15601722.

[38] R. Lowe, L.F. Chiu, T. Oreszczyn, Socio-technical case study method in building performance evaluation, Build. Res. Inf. 46 (2017) 469-484, doi:10.1080/09613218.2017.1361275.

[39] L. Lutzenhiser, Social and Behavioral Aspects of Energy Use, 2003.

[40] L. Lutzenhiser, K. Janda, R. Kunkle, C. Payne, Understanding the Response of Commercial and Institutional Organizations to the California energy Crisis, California Energy Commission, 2002.

[41] N.D. Mortimer, A. Ashley, J.H.R. Rix, Detailed energy surveys of nondomestic buildings, Environment and Planning B: Planning and Design 27 (2000) 25-32, doi:10.1068/b2572.

[42] Mtp2009. BNCR CR02: Walk-in cool rooms government standards evidence base 2009: Reference Scenario DOI:

[43] Mtp, BNCR RDC03: Refrigerated Display Cases Government Standards Evidence Base 2009: Policy Scenario, 2009 [Online]. Available:. http://efficient-products.ghkint.eu/spm/download/doc ument/id/912.pdf.

[44] S. Mudie, E. Essah, A. Grandison, R. Felgate, Benchmarking energy use in licensed restaurants and pubs, CIBSE Technical Symposium (2013).

[45] Nifes Consulting Group, Scottish Butchers guide to Savings Energy, 2012 [Online]. TRUST, C. Available:. https://www.carbontrust.com/media/383509/ctg082-scottish-butchers-guide-to-saving -energy.pdf.

[46] Y. Parag, K.B. Janda, More than filler: Middle actors and socio-technical change in the energy system from the "Middle-Out", Energy Research and Social Science 3 (2014) 102-112. http://dx. doi.org/10.1016/i.erss.2014.03.014.

[47] Y. Parag, K.B. Janda, More than filler: Middle actors and socio-technical change in the energy system from the "middle-out", Energy Research and Social Science 3 (2014) 102-112, doi:10.1016/j.erss.2014.07.011.

[48] M. Patton, Qualitative Research And Evaluation Methods, 2002.

[49] A. Revell, R. Blackburn, The business case for sustainability? an examination of small firms in the UK's construction and restaurant sectors, Business Strategy and the Environment 16 (2007) 404-420, doi:10.1002/bse.499.

[50] A. Sa, S. Paramonova, P. Thollander, E. Cagno, Classification of industrial energy management practices: A case study of a swedish foundry, Energy Procedia 75 (2015) 2581-2588. https://doi. org/10.1016/j.egypro.2015.07.311. 
A. Sbaraini, S.M. Carter, R.W. Evans, A. Blinkhorn, How to do a grounded theory study: a worked example of a study of dental practices, BMC Med Res Methodol 11 (2011) 128, doi:10.1186/1471-2288-11-128.

[52] Sustainable Energy Authority of Ireland, Significant Energy Users Assessment Tool, 2012 [Online].

[53] F. Wade, R. Hitchings, M. Shipworth, Understanding the missing middlemen of domestic heating: Installers as a community of professional practice in the united kingdom, Energy Research \& Social Science 19 (2016) 39-47. https://doi.org/10.1016/j.erss.2016.05.007.

[54] J.Walton, JWIaC1992. Making the theoretical case. 121-137. DOI:

[55] R.K. Yin, Case Study Research and Applications : Design and Methods, SAGE Publications, Inc, Thousand Oaks, California, 2018.

[56] https://www.nytimes.com/2002/05/09/business/california-may-have-had-big-role-in-enron-s-fall. html. 2002. [accessed 18 November 2019].

\section{Footnotes}

\section{Text Footnotes}

$\left[{ }^{1}\right]$ The BEES survey defines small shops as small premises used for betting shops, or for conducting the retail sale of both food and non-food consumer goods such as clothing, books, toys, sporting goods, office supplies, hardware, and electronics. Small shops were typically occupied by micro organisations employing fewer than 10 people (73 per cent and 66 per cent, respectively).

$\left.{ }^{2}\right]$ Quasi-intervention in this context meant undertaking an energy audit as part of the study and producing a summary of audit recommendations for each of the retailers to use as a basis for subsequently exploring potential for energy efficiency adoption.

$\left[{ }^{3}\right]$ Estimations of energy efficiency potential were calculated using the SEAI energy assessment tool, using energy use data from on-site equipment (e.g. collection of name-plate ratings for refrigerators) where available, or using alternative sources (e.g. Market Transformation Programme stock energy use data) where not. Assumptions for new energy efficient equipment were based on desk research, selecting market available energy efficient options for technologies including lighting, refrigeration, HVAC and behavioural changes, which did not require equipment replacement.

$\left[{ }^{4}\right]$ Review of tenancy agreements was beyond the scope of this work, but when questioned, all three retailers believed that their tenancy agreements were structured such that the landlord was only responsible for the building 'shell', and all other elements including HVAC were their responsibility to provide and maintain. There appeared to be a grey area regarding the 
street facing windows and facades, whereby one retailer noted that when that was upgraded the financing of it was split 50/50.

$\left.{ }^{5}\right]$ Third party intermediaries (TPIs) are organisations or individuals that give energy related advice, aimed at helping consumers buy energy and/or manage their energy needs. TPIs include switching sites, energy brokers and any company that offers support with energy procurement.

$\left[{ }^{6}\right]$ For the Fishmonger this was not relevant as it was an open fronted shop, with no door.

$\left[{ }^{7}\right]$ Social and technological innovations are commonly seen as either being induced from the 'top-down', e.g., by policymakers-or evolving from the 'bottom-up', e.g., by consumers. Instead, a 'middle-out' perspective focuses on agents of change or 'middle actors' that are located in the middle, between the top and the bottom. and Parag \& Janda [34] describe how middle actors include (but are not limited to) such groups as building professionals, religious congregations, and commercial property owners ([46]a). In recent years, these and other authors have further developed the middle-out perspective to address providers of housing refurbishment [35, 36], heating engineers [53], community-based organizations [26], facilities managers [25], social housing providers [8], and actors involved in energy storage [18].

\section{Queries and Answers}

Query: Please confirm that givennames and surnames have been identified correctly.

Answer: Yes

Query: Please check funding information and confirm its correctness.

Answer: I checked and we only have to mention one grant number, so have updated

Query: Please check funding information and confirm its correctness.

Answer: as per $\mathrm{q} 2$

Query: Please check the length of the author initials and confirm if correct. Else provide the updated reference.

Answer: Apologies - this is a chapter written by John Walton in this book, so the reference should be:

This reference should be: Walton, John 'Making the Theoretical Case', in Ragin, Charles C. and Becker, Howard S. (eds), What is a Case? Exploring the Foundations of Social Inquiry. Cambridge: Cambridge University Press, pp. 121137. 
Query: Please check the length of the author initials and confirm if correct. Else provide the updated reference.

Answer: as per q4 